\title{
Nepal medical council and continuous professional development
}

\author{
Dr. Ramesh Kant Adhikari \\ Professor, Department of Paediatrics, Kathmandu Medical College Teaching Hospital, Kathmandu, Nepal.
}

$D^{2}$ octors as professional individuals need to work for their professional development through a continuous process of education. A doctor needs this to serve the patient well with the latest modalities of diagnostics and therapeutics; society demands from her/ him to assure itself that its doctors are competent and up to date and it is also desired by doctors themselves to keep their work interesting and avoid boredom and burn out ${ }^{1}$. It is in the interest of the doctors that their education continues after graduate and postgraduate training. In fact, doctors' work offers them opportunities to learn from their patients, their relatives and from colleagues and peers. In the absence of awareness and mechanism to record them, such learning becomes a matter of chance and not credited for. It is a professional responsibility of every doctor. In addition, to make it effective, the medical colleges and professional societies need to make necessary arrangements to facilitate such continuous professional development and the regulatory authorities demand that the doctors demonstrate evidence of such continued education.

Medical councils regulate the medical practice in most of the countries in the world. One cannot practice medicine without getting a license from their national medical council or equivalent authority in a country. The regulatory authority which licenses doctors to practice medicine needs to ensure that the doctors they have licensed are well informed of the recent developments in principles of practice of medicine and competent in using the skills required in the practice and also in use of latest modalities of diagnostics and therapeutics. They are also concerned that the licensee medical professionals have maintained their skills required to serve the people.

The regulatory authorities in the developed countries ${ }^{2}$ have tried to ensure these abilities in doctors through a process of licensing and re-licensing. Recertification or relicensing requires that the doctors demonstrate that they have been continuing their education for the purpose of professional development. However, the situation in most of the developing countries is different and licensing of doctors in such countries is for life and there is no obligation for doctors to demonstrate any evidence of their learning after they had completed their training. It does not mean that the doctors in such countries stop learning; most of the successful professionals in these countries do continue and actively seek opportunities for professional development and continue to learn through their clinical work, interaction with peers and attendance at formal workshops and training programmes besides attending the seminars and conferences. They however, lack a mechanism which would recognize the learning they have been acquiring through various means and give them credit for it.

Nepal Medical Council (NMC), cognizant of this situation had been working on a plan to facilitate continuing professional development of doctors and establish a mechanism that would demand from doctors to demonstrate that they had been continuing their education.

Role of NMC in protecting the health of the people by ensuring efficient and ethical medical practice by the doctors has been recognized by the Nepal Medical Council Act $^{3}$. Nepal Medical Council, in order to perform the tasks entrusted to it has developed the following mechanisms:

a. Regulation of the medical education system in the country: through development of minimum requirements to establish medical colleges and monitoring of the educational institutes to see that they fulfil these requirements.

b. Licensing of the medical practitioners who have duly completed the approved graduate or postgraduate course from recognized medical colleges and have successfully passed the licensing examination conducted by NMC and maintaining a register of such doctors.

c. Advising the doctors on ethical norms of medical practice by issuing code of ethics for doctors to ensure that they are familiar with their roles and responsibilities and the right way to discharge them so that they practice medicine ethically. 
d. Registering, investigating and taking actions in response to the complaints against medical practitioners.

The current system has not been able to monitor the competence of medical practitioners on a regular basis. The license given to a doctor is for life and there is no mechanism to oversee the competence of a doctor over the years: there may be waning of his or her knowledge and skills, newer challenges might have emerged and the doctors may be unaware of or incapable of responding to them. The current arrangement is likely to result in situations of wrong practice or malpractice to the detriment of people's health.

In order to correct this situation, $\mathrm{NMC}^{4}$ is planning to establish a system which will provide opportunities for continuing professional development to the doctors. A doctor will have to show evidence of participating in CPD activities and it will be a mandatory requirement to remain in the NMC register. Thus, ultimately, every doctor will have to make sure that he or she is continuing to learn in order to re-register themselves with NMC.

The council is in the process of taking the following steps to establish the system: a policy decision that clearly state that the doctors would require demonstrating mandatory evidence of their participation in CPD activities in order to maintain their licence to practice medicine; establishment of a National CPD Board to implement the process and supervise various activities. It is planned to establish a secretariat which will provide administrative support.

Though the areas in which a doctor would seek education will be decided by her or his perceived needs, there are certain "must know" areas in which every doctor need to maintain their knowledge and skills. Some of these areas are: skills in cardiopulmonary resuscitation, communication skills and medical ethics, rational use of drugs and therapeutics and infection prevention. The council would facilitate creation of opportunities for every doctor to get training in these areas. NMC would have to engage medical colleges, tertiary hospitals and professional bodies in creation of such opportunities. These organizations have additional responsibilities of conducting their affairs in such a way that these would facilitate CPD of the doctors working with them. Such activities include regular case presentation, morbidity and mortality seminar, journal clubs and workshops on new skills. NMC and Ministry of Health would have to start monitoring of such activities while approving or renewing of the license of such institutions.
NMC will also have to develop the criteria accrediting the providers of learning opportunities ("CPD", henceforth). These criteria should include the details for the trainers and training institutions. The Medical Colleges, professional societies or any organization can fulfil these criteria and start providing CPD to the doctors. The terms of providing CPD by an organization will be decided by the organizations but these will have to be approved by the NMC.

NMC has plans to make a policy decision requiring the doctors to re-register within a period of five years since the date CPD system comes in effect. Doctors applying for re-registration will have to demonstrate that they had been undergoing continuous professional development as evidenced by their participation in various educational activities. Subsequently, re-registration will have to be done every three years. The "must know" or mandatory topics and the credit points it would carry may differ from time to time. It has been proposed that for the first time re-registration, every doctor will have to earn 100 credit points within a period of five years and $30 \%$ of which will have to be in the mandatory topics mentioned above.

The plan envisages that the council would facilitate the establishment of a system that would provide opportunities for every doctor to get trained in the mandatory areas. It would also help professional bodies, medical colleges and tertiary hospitals to establish a system of providing training and learning experiences to the doctors. NMC plans to train master trainers and help to equip the willing institutions for this purpose. NMC plan also includes a simple computerized online registration system on which every CPD provider or recipient can log and register. CPD providers would get approval for conducting the activity and submit online the list of participants who had received training and that would be registered automatically. A system of recording of credit points earned by every doctor will track the performance of each practitioner registered with it. This will help to corroborate the submission made by each doctor about his or her performance regarding CPD.

\section{ROLE OF MEDICAL COLLEGES, PROFESSIONAL SOCIETIES, ASSOCIATIONS AND ORGANIZATIONS}

Medical colleges, professional societies and associations have to play a very constructive and active role in order to make this system work. They will have to work closely, in a coordinated way with NMC to make it possible. They will have to create a system of providing CPD to the 
doctors and conduct such activities on a regular basis and make decisions regarding the human resources (trainers, lecturers or resource persons), equipment, space and time for CPD. NMC and CPD provider agencies would have to agree on the financial arrangements for conducting the training and other CPD activities. In addition, mechanism to assure quality of the CPD activities need to be developed in collaboration with the council. All CPD providers need to follow the guidelines given by National CPD Board in order to get recognized and register it online with CPD System. Online CPD registration will help these activities to be publicised so that doctors interested in the educational activity can participate in any activity which suits their needs and resources.

\section{INDIVIDUAL DOCTORS' RESPONSIBILITIES}

The doctors are required to participate in the mandatory training on basic life support and cardiopulmonary resuscitation, communication skills, professionalism and medical ethics; rational use of diagnostics and therapeutic modalities and infection control. In addition, they have to keep on attending the educational activities conducted by their professional societies, medical colleges or hospitals. The subjects of such educational activities are left to the interest, need and choice of individual doctors. The doctors would have to make sure that the educational activities they are participating in have been duly accredited by CPD Board of the Nepal Medical Council. NMC website on CPD will provide the information about the credit points of every educational activity.

NMC CPD Board would facilitate this process by making it easy for individuals to get into the online registration system for finding the accredited programmes, their schedule and expenses etc. This registration system will also allow the registered doctors to submit their credit points online so that NMC CPD Board would have record of all the CPD points earned by a doctor. This will facilitate re-registration as there will be a link between Registration Committee and CPD unit of NMC.

\section{RESPONSIBILITIES OF PROVIDER OR ORGANISER OF CPD ACTIVITY}

Any organization can be a CPD provider but to start with it is envisaged that medical colleges, professional associations or organizations and tertiary hospitals would take this role. Once an agency decides to conduct the educational activity, it should clarify the objectives of the programme; identify the teaching learning experiences to be offered and the methods used to provide them. A mechanism should be planned to assess achievements of the participants in terms of educational objectives of the activity. The provider agency would have to publicise the event along with the agenda, list of resource persons and their accreditation status with NMC CPD Board and the date and venue of the programme and the costs if any and the number of seats available. Every CPD activity will have to be accredited and credit points to be earned specified in advance. The CPD providers should submit the list of participants who had successfully completed the activity and earned the stipulated credit points to CPD Board so that it can register the credit points in each participant's CPD account. If there is any commercial sponsorship for the activity, it should be disclosed to the presenters, resource persons, learners and accrediting bodies. It is the responsibility of the CPD providers to ensure that the sponsorship or funding by any commercial enterprise does not influence the content of the educational activity.

\section{WAY FORWARD}

NMC had been able to develop a tentative plan that would make CPD activity a necessity for every doctor if they want to continue clinical practice. However, there are quite a few substantial challenges. NMC will have to disseminate this information more widely and try to clarify questions and uncertainties among the registered doctors. The next step would be to take all possible CPD providers in confidence and help them to develop programmes for providing CPD. A piloting of the proposed training plan and registration of CPD activities and participation in these activities need to be carried out before finalizing the scheme and declaring the dates for making CPD credit points mandatory for all the doctors.

\section{REFERENCES}

1. World Federation of Medical Education. Continuing professional development (CPD) of medical doctors: WFME Global Standards for Quality Improvement. Denmark: University of Copenhagen; 2003.

2. General Medical Council. Continuing Professional Development: Guidance for all doctors [Internet]. Manchester: General Medical Council; 2012 Jun.
Available from: http://www.gmc-uk.org/CPD guidance_June_12.pdf_48970799.pdf

3. Government of Nepal. Nepal Medical Council (third amendment) Rules and Regulations. Kathmandu: Government of Nepal; 2000.

4. Nepal Medical Council, CPD committee. Report of the stakeholders' meeting on CPD in Nepal. Kathmandu: Nepal Medical Council; 2013 Dec 28. 